\title{
Eating disorders and pregnancy: Proposed treatment guidelines for obstetricians and gynecologists
}

\author{
Victor Fornari $^{1,2 *}$, Ida Dancyger ${ }^{1,2}$, Jessica Renz ${ }^{3}$, Rebecca Skolnick ${ }^{3}$, Burton Rochelson ${ }^{2,4}$ \\ ${ }^{1}$ Division of Child \& Adolescent Psychiatry, Department of Psychiatry, Zucker Hillside Hospital, Glen Oaks, New York, USA \\ ${ }^{2}$ Hofstra North Shore-LIJ School of Medicine, Uniondale, New York, USA \\ ${ }^{3}$ Center for Eating Disorders, Division of Child \& Adolescent Psychiatry, Department of Psychiatry, Cohen Children’s Medical Cen- \\ ter, New Hyde Park, New York, USA \\ ${ }^{4}$ Division of Maternal Fetal Medicine, Department of Obstetrics \& Gynecology, North Shore-LIJ Health System, Manhasset, New \\ York, USA \\ Email: ${ }^{\text {vffornari@nshs.edu }}$
}

Received 10 January 2014; revised 5 February 2014; accepted 13 February 2014

Copyright (c) 2014 Victor Fornari et al. This is an open access article distributed under the Creative Commons Attribution License, which permits unrestricted use, distribution, and reproduction in any medium, provided the original work is properly cited. In accordance of the Creative Commons Attribution License all Copyrights @ 2014 are reserved for SCIRP and the owner of the intellectual property Victor Fornari et al. All Copyright (C 2014 are guarded by law and by SCIRP as a guardian.

\section{ABSTRACT}

Pregnant women with eating disorders are at risk for multiple complications to both the woman and the fetus. Eating disorders are particularly prevalent among adolescent girls and young women. This paper suggests a road map for the obstetrician gynecologist caring for women who either have an active eating disorder, report a history of a prior eating disorder, or when the clinician suspects that the woman may have an eating disorder which has not been previously identified. Proposed treatment guidelines are outlined.

\section{KEYWORDS}

\section{Eating Disorders; Pregnancy; Treatment Guidelines}

\section{INTRODUCTION}

Eating disorders are serious psychiatric diagnoses with a number of associated medical complications. In fact, studies have shown that eating disorders, particularly anorexia nervosa (AN), have higher rates of premature deaths than most other psychiatric illnesses [1]. Eating disorders are particularly prevalent among adolescent girls and young women. The average point prevalence rates for AN and bulimia nervosa (BN) in young females aged $11-35$ are 0.3 and $1 \%$, respectively [2]. In this group, the overall incidence of $\mathrm{AN}$ is at least 8 per 100,000 population per year and the incidence of $\mathrm{BN}$ is at least 12 per 100,000 population per year [3].

${ }^{*}$ Corresponding author.
Healthy young women typically seek medical care from obstetricians and gynecologists. In this group, 90\% of eating disorders develop before the age of 25 [4]. Subclinical syndromes are prevalent in women seeking obstetrical care and the estimated prevalence of eating disorders in pregnant women in the United States is approximately $1 \%$. In this group, it is probable that 3 out of every 100 women have a diagnosable eating disorder and that 15 out of these 100 may be experiencing a subclinical syndrome [5]. Thus, it is imperative that obstetricians and gynecologists become educated on the identification of eating disorders and be prepared to take necessary clinical steps when an eating disorder is suspected.

Signs of a suspected eating disorder may include: failure to make expected weight goals, intense fear of gaining weight, preoccupation with feeling fat, and abnormal electrolytes, such as a low serum potassium level. Family members may sometimes report their concerns about their spouse or loved one to the physician. The family concerns need to be carefully assessed, and not discounted.

Ideally, obstetricians will assess and recognize the signs of an eating disorder both before and during pregnancy. Pregnancy is a particularly sensitive period of time that involves developmental changes in physical, social, and psychological areas for most women. One of the most significant physical changes during pregnancy is weight gain. It is recommended that women of normal weight (i.e. body mass index (BMI) between 18.5 and 24.9) gain 25 - 35 lbs., and that underweight women (BMI less than 18.5) gain 28 - 40 lbs. during pregnancy [6].

Research findings on the psychological effects of this weight gain in pregnant women with eating disorders are 
inconsistent. For example, in a survey of 43 women with eating disorders, Lemberg and Phillips (1989) found that while $85.7 \%$ of respondents feared losing control of weight gain during pregnancy, the majority of participants did not equate pregnancy with feeling fat or unattractive. Furthermore, for about half of participants, the pregnancy reportedly gave them a sense of responsibility. However, about one quarter reported feeling confused and resentful of the unborn child. Research suggests that despite fears of losing control of weight gain [7], disordered eating behaviors tend to decrease during pregnancy $[8,9]$. Eating disorder symptoms have also been shown to worsen after pregnancy [8]. Thus, the time period during and after pregnancy may necessitate treatment for women with prior eating disorder diagnoses, including interventions that target concerns related to weight and shape.

In addition to psychological repercussions, studies and clinical practice have demonstrated that eating disorders, primarily AN, can have deleterious physical effects on the mother and fetus [10]. Pregnant women with eating disorders have a particularly high risk for negative birth outcomes including spontaneous abortion, preterm labor, delivery by cesarean section, and obstetrical complications $[11,12]$. Case reports have described perinatal mortality. Commonly cited complications during pregnancy in women with eating disorders include inadequate or excessive weight gain during pregnancy and hyperemesis gravidarum $[13,14]$. Risks to the fetus include a greater likelihood of low birth weight, smaller head circumference, microcephaly, and intrauterine growth restriction [15].

Given the number of potential complications linked to pregnancy in women with eating disorders, there are important implications for reproductive endocrinologists and obstetrician gynecologists. In the Avon Longitudinal Study of Parents and Children, Easter, Treasure, and Micali (2011) found that women with a history of AN and/or BN were more likely to have seen a doctor for fertility problems. Furthermore, women with both AN and $\mathrm{BN}$ were more likely to take longer than six months to conceive, and to require fertility treatment to conceive [16]. Compared to the general population, women with a history of AN were less likely to have intentional pregnancies, and women with AN and/or BN were more likely to report negative feelings toward their pregnancies at 18 weeks of gestation [16]. Thus, it is important for fertility specialists to assess eating disorder symptoms in order to provide effective and informed treatment.

\section{WHAT TO DO DURING INITIAL ASSESSMENT}

The initial assessment of a pregnant woman is a critical opportunity to determine if the woman has had, or currently suffers from, an eating disorder. The earlier an eating disorder can be detected, the more likely it is that intervention will occur to protect both the woman and the fetus. Given the nature of eating disorders, many women may withhold information, or may believe that they do not have a problem. Thus, it is essential that obstetricians educate themselves about eating disorder warning signs, evaluate what patients verbally report, and monitor weight changes over time. If the obstetrician has not been following the patient for an extended time before pregnancy, it would be good practice to obtain a history of weight gain and loss from the patient's gynecologist or primary care provider, and to calculate pre-pregnancy BMI. Furthermore, if the patient is a minor (in New York State a pregnant teenager is not considered a minor, and nothing can be discussed with the parent without consent), we recommend that obstetricians ask the patient's parents about a potential eating disorder history. Obstetricians can ask the parents a very simple question, such as, "Has your daughter ever struggled with weight and eating problems?" This question should also be asked directly to the patient.

Researchers have proposed a number of assessment tools and questions that can be used in the initial assessment of pregnant women. For example, Franko and Spurrell (2000) suggest that obstetricians use the Eating Disorder Examination [17] to determine the presence of an eating disorder [13]. Andersen and Ryan (2009) have suggested using shorter and more practical measures to assess eating disorders without using formal inventories. For instance, they propose that obstetrician gynecologists use screening questions from the SCOFF questionnaire $[4,18]$. This measure includes questions about eating until feeling uncomfortably full, worrying about losing control over how much one eats, losing over 14 pounds in the past three months, thinking one is fat when others say otherwise, and food dominating one's life. Andersen and Ryan (2009) also propose that obstetricians ask patients, "What is it like for you to be weighed at every visit?” [4].

\section{The SCOFF Questions}

- Do you make yourself Sick because you feel uncomfortably full?

- Do you worry that you have lost Control over how much you eat?

- Have you recently lost more than One stone (14 lb) in a 3-month period?

- Do you believe yourself to be Fat when others say you are too thin?

- Would you say that Food dominates your life?

Regardless of a patient's pregnancy status, we propose including screening questions that address eating disorders (such as those on the SCOFF questionnaire) on intake forms and in interviews at obstetric and gy- 
necology offices. We believe that if an eating disorder can be identified prior to pregnancy, there is a better likelihood that the patient will obtain appropriate intervention before potentially becoming pregnant in the future. Given the high prevalence of eating disorders among adolescent girls and young women, we propose that obstetrician gynecologists ask all of their patients at each visit, "Have you ever, or do you currently, struggle with weight and/or eating problems?" Although the patient may deny a history of disordered eating or behavior, it would be useful for obstetricians to educate those patients suspected of maladaptive eating attitudes and behaviors about the potential medical consequences of eating disorders, including difficulty conceiving and risks during pregnancy to the woman and her fetus [19].

\section{POSSIBLE SIGNS OF EATING DISORDERS BEFORE AND DURING PREGNANCY}

Familiarity with warning signs and early detection for pregnant women with eating disorders is crucial for providers of obstetrical care, as there is some evidence that anorexic and bulimic women are reluctant to disclose their histories and symptoms to healthcare professionals. The nature of the eating disorder itself often results in feelings of shame and guilt in the patient, making detection of eating disorder symptoms difficult [13]. It is essential to assess for the possible signs of an eating disorder that may have existed before pregnancy as well as during a current pregnancy. These include having a preconception or first trimester BMI of less than 18, amenorrhea before pregnancy, history of miscarriage, infertility, possible food restriction, and failure to make appropriate weight gain during pregnancy. Inadequate weight gain, particularly in the second trimester, should be investigated thoroughly, from both psychological and medical perspectives [13].

Many of the current articles in the literature assume that most health care professionals are familiar with the characteristic symptoms of eating disorders [13]. Unfortunately, this is not always the case. Data collected from physicians working in obstetrics and gynecology suggest that although a majority assess body weight, exercise, dieting habits, and BMI, less than half assessed for a history of eating disorders or body image concerns. Perhaps most importantly, approximately $90 \%$ of respondents reported residency training in diagnosing and treating eating disorders as "barely adequate" or less. Although most physicians knew that an eating disorder could negatively impact pregnancy, only half viewed eating disorder assessment as their responsibility, because of gaps in knowledge, assessment skills, and confidence in their training regarding eating disorders [20].
It is strongly recommended that current and future obstetrics and gynecological providers be made aware of the importance of assessing for signs and symptoms of eating disorders in addition to increasing their knowledge base and confidence about being able to do so. We propose including education about eating disorder signs and symptoms in Obstetrics and Gynecology resident training programs so physicians are made aware of this possibility when treating patients.

\section{PROPOSED GUIDELINES}

\subsection{For Patients with $\mathrm{BMI} \leq 18.5$ (To Be} Determined if Mild, Moderate, or Severe Underweight) Pre-Conception or during First Trimester, Inadequate Weight Gain in Second and Third Trimesters, or When Optimal Fetal Growth Is Retarded (Table 1)

1) Patient reports a history of eating disorder: Nutritional Consultation; BMI; Electrolytes; Bone Density; Obtain history of mental health treatment, including hospitalizations and medications.

2) Patient has a current eating disorder: Nutritional Consultation; BMI; Electrolytes; Bone Density; Obtain history of mental health treatment, including hospitalizations and medications; Refer to mental health treatment professional with eating disorder expertise; Obtain consent to speak with current or prior mental health provider.

3) Physician suspects an eating disorder: Nutritional Consultation; BMI; Electrolytes; Bone Density; Refer for mental health consultation to professional with eating disorder expertise.

4) Patient develops an eating disorder during pregnancy: Nutritional Consultation; BMI; Electrolytes; Bone Density; Refer for mental health consultation to professional with eating disorder expertise.

\subsection{What to Do if Patient Refuses Recommendations}

This may represent the greatest challenge for the obstetrician. Failure to make weight goals during pregnancy may suggest an emergent or require an urgent psychiatric consultation. Determination of capacity to make decisions becomes critical. At this juncture, the determination of whether the patient may require coercive treatment, including the possibility of involuntary psychiatric care, requires consultation between the psychiatrist and the patient's obstetrician. Family involvement, even over the objection of the patient, may be medically necessary [21].

\subsection{When to Consider Emergency Psychiatric Evaluation}

This is reserved for serious safety considerations. Failure 
Table 1. Proposed guidelines for obstetricians and gynecologists for pregnant patients or patients attempting to conceive.

\begin{tabular}{ccccc}
\hline & $\begin{array}{c}\text { Patient Reports History } \\
\text { of Eating Disorder }\end{array}$ & $\begin{array}{c}\text { Patient Has Current } \\
\text { Eating Disorder }\end{array}$ & $\begin{array}{c}\text { Physician Suspects } \\
\text { Eating Disorder }\end{array}$ & $\begin{array}{c}\text { Patient Develops } \\
\text { Eating Disorder } \\
\text { During Pregnancy }\end{array}$ \\
\hline Nutrition Consultation & $\mathrm{X}$ & $\mathrm{X}$ & $\mathrm{X}$ & $\mathrm{X}$ \\
BMI & $\mathrm{X}$ & $\mathrm{X}$ & $\mathrm{X}$ & $\mathrm{X}$ \\
Electrolytes & $\mathrm{X}$ & $\mathrm{X}$ & $\mathrm{X}$ & $\mathrm{X}$ \\
Bone Density & $\mathrm{X}$ & $\mathrm{X}$ & $\mathrm{X}$ \\
$\begin{array}{c}\text { History of Mental Health Treatment } \\
\text { (including Hospitalizations and Medications) }\end{array}$ & $\mathrm{X}$ & $\mathrm{X}$ & $\mathrm{X}$ \\
$\begin{array}{c}\text { Refer to Mental Health Treatment Professional } \\
\text { with Eating Disorder Expertise }\end{array}$ & & $\mathrm{X}$ & \\
Obtain Consent to Speak with Current or & & & \\
Prior Mental Health Provider & & & \\
\hline
\end{tabular}

"BMI $<18.5$ = underweight.

to make weight gain, in turn jeopardizing fetal development, may necessitate emergent evaluation. When the obstetrician suspects an eating disorder, and the patient denies one, this may require referral to an emergency department for emergent psychiatric evaluation. Concerns regarding a family crisis, domestic violence, suicidal risk, and contradictory safety information between the patient and her family may all require emergency psychiatric care.

\subsection{When to Consider Involvement of Child Protective Services}

In certain rare circumstances, if the obstetrician is concerned that the woman is unable to care for her infant post-partum, a referral to the local child protective services may be considered.

\section{CONCLUSION}

The obstetrician is in a unique position to evaluate, identify, treat, and refer women with suspected or confirmed eating disorders that may jeopardize fetal development and outcome of pregnancy. We suggest that all practicing obstetricians develop a relationship with a mental health provider with special expertise in eating disorders to discuss and consult regarding the clinical management of their patients. The guidelines proposed here offer the practicing obstetrician a road map to navigate this challenging, yet very important terrain.

\section{REFERENCES}

[1] Harris, E.C. and Barraclough, B. (1998) Excess mortality of mental disorder. British Journal of Psychiatry, 173, 11-53. http://dx.doi.org/10.1192/bjp.173.1.11

[2] Hoek, H. (2006) Incidence, prevalence and mortality of anorexia nervosa and other eating disorders. Current Opinion in Psychiatry, 19, 389-394. http://dx.doi.org/10.1097/01.yco.0000228759.95237.78
[3] Hoek, H. and van Hoeken, D. (2003) Review of the prevalence and incidence of eating disorders. International Journal of Eating Disorders, 34, 383-396. http://dx.doi.org/10.1002/eat.10222

[4] Andersen, A.E. and Ryan, G.L. (2009) Eating disorders in the obstetric and gynecological patient population. $\mathrm{Ob}$ stetrics and Gynecology, 114, 1353-1367. http://dx.doi.org/10.1097/AOG.0b013e3181c070f9

[5] Chizawsky. L. and Newton, M. (2006) Eating disorders: Identification and treatment in obstetrical patients. Nursing for Women's Health, 16, 482-488.

[6] Institute of Medicine (2009) Weight gain during pregnancy: Reexamining the guidelines. The National Academies Press, Washington, D.C.

[7] Lemberg, R. and Phillips, J. (1989) The impact of pregnancy on anorexia nervosa and bulimia. International Journal of Eating Disorders, 8, 285-295. http://dx.doi.org/10.1002/1098-108X(198905)8:3<285::A ID-EAT2260080304>3.0.CO;2-P

[8] Crow, S.J., Agras, W.S., Crosby, R., Halmi, K. and Mitchell, J.E. (2008) Eating disorder symptoms in pregnancy: A prospective study. International Journal of Eating Disorders, 41, 277-279. http://dx.doi.org/10.1002/eat.20496

[9] Blais, M.A., et al. (2000) Pregnancy: Outcome and impact on symptomatology in a cohort of eating-disordered women. International Journal of Eating Disorders, 27, $140-149$ http://dx.doi.org/10.1002/(SICI)1098-108X(200003)27:2 $<140:$ :AID-EAT2>3.0.CO;2-E

[10] Mazer-Poline, C. and Fornari, V. (2009) Anorexia nervosa and pregnancy: Having a baby when you are dying to be thin-Case report and proposed treatment guidelines. International Journal of Eating Disorders, 42, 382384. http://dx.doi.org/10.1002/eat.20607

[11] Resch, M. and Szendei, G. (2002) Gynecologic and obstetric complications in eating disorders. Orvosi Hetilap, 143, 1529-1532.

[12] Bulik, C.M., et al. (1999) Fertility and reproduction in women with anorexia nervosa: A controlled study. Journal of Clinical Psychiatry, 60, 130-135. 
http://dx.doi.org/10.4088/JCP.v60n0212

[13] Franko, D.L. and Spurrell, E.B. (2000) Detection and management of eating disorders during pregnancy. Obstetrics and Gynecology, 95, 1353-1367. http://dx.doi.org/10.1016/S0029-7844(00)00792-4

[14] Rochelson, B., Vohra, N., Darvishzadeh, J. and Pagano, M. (2003) Low prepregnancy ideal weight:height ration in women with hyperemesis gravidarum. Journal of Reproductive Medicine, 48, 422-424.

[15] Kouba, S., Hällström, T., Lindholm, C. and Hirschberg, A.L. (2005) Pregnancy and neonatal outcomes in women with eating disorders. Obstetrics and Gynecology, 105, 255-260. http://dx.doi.org/10.1097/01.AOG.0000148265.90984.c3

[16] Easter, A., Treasure, J. and Micali, N. (2011) Fertility and prenatal attitudes towards pregnancy in women with eating disorders: Results from the Avon Longitudinal Study of Parents and Children. BJOG: An International Journal of Obstetrics \& Gynaecology, 118, 1491-1498. http://dx.doi.org/10.1111/j.1471-0528.2011.03077.x

[17] Fairburn, C.G. and Cooper, Z. (1993) The eating disorder examination. In: Fairburn, C.G. and Wilson, G.T., Eds., Binge eating: Nature, assessment, and treatment (12th ed.), Guilford Press, New York, 317-356.

[18] Morgan, J.F., Reid, F. and Lacey, J.H. (1999) The SCOFF questionnaire: Assessment of a new screening tool for eating disorders. British Medical Journal, 319, 1467-1468. http://dx.doi.org/10.1136/bmj.319.7223.1467

[19] Mehler, P.S., Birmingham, L.C., Crow, S.J. and Jahraus, J.P. (2010) Medical complications of eating disorders. In: Grilo, C.M. and Mitchell, J.E., Eds., The treatment of eating disorders: A clinical handbook, Guilford Press, New York, 66-80.

[20] Leddy, M.A., Jones, C., Morgan, M.A. and Schulkin, J. (2009) Eating disorders and obstetric-gynecological care. Journal of Women's Health, 18, 1395-1431. http://dx.doi.org/10.1089/jwh.2008.1183

[21] Guarda, A.S. and Coughlin, J.W. (2009) Treatment resistance: Persuasion, perceived coercion and compulsion. In: Dancyger, I.F. and Fornari, V.M., Eds., Evidence based treatments for eating disorders: Children, adolescents and adults, Nova Science Publishers, New York, 171-186.

\section{ABBREVIATIONS}

AN: Anorexia Nervosa;

BN: Bulimia Nervosa;

BMI: Body Mass Index;

SCOFF: Sick Control One Fat Food. 